University of Nebraska - Lincoln

DigitalCommons@University of Nebraska - Lincoln

Nebraska Cooperative Fish \& Wildlife Research Nebraska Cooperative Fish \& Wildlife Research Unit -- Staff Publications

Unit

7-19-2019

How characteristic is the species characteristic selection scale?

Erica F. Stuber

Joseph J. Fontaine

Follow this and additional works at: https://digitalcommons.unl.edu/ncfwrustaff

Part of the Aquaculture and Fisheries Commons, Environmental Indicators and Impact Assessment Commons, Environmental Monitoring Commons, Natural Resource Economics Commons, Natural Resources and Conservation Commons, and the Water Resource Management Commons

This Article is brought to you for free and open access by the Nebraska Cooperative Fish \& Wildlife Research Unit at DigitalCommons@University of Nebraska - Lincoln. It has been accepted for inclusion in Nebraska Cooperative Fish \& Wildlife Research Unit -- Staff Publications by an authorized administrator of DigitalCommons@University of Nebraska - Lincoln. 


\title{
How characteristic is the species characteristic selection scale?
}

\author{
Erica F. Stuber (iD | Joseph J. Fontaine
}

Nebraska Cooperative Fish and Wildlife Research Unit, School of Natural Resources, University of Nebraska-Lincoln, Lincoln, Nebraska

\section{Correspondence}

Erica F. Stuber, Nebraska Cooperative Fish and Wildlife Research Unit, School of Natural Resources, University of NebraskaLincoln, 511 Hardin Hall, Lincoln, NE, 68583, USA.

Email: efstuber@gmail.com

Present address

Erica F. Stuber, Yale University, New Haven, Connecticut

Funding information

Nebraska Game and Parks Commission, Grant/Award Number: Federal Aid in Wildlife Restoration project W-98-R

Editor: Nick Issac

\begin{abstract}
Aim: The importance of framing investigations of organism-environment relationships to interpret patterns at relevant spatial scales is increasingly recognized. However, most research related to environmental relationships is single-scaled, implicitly or explicitly assuming that a "species characteristic selection scale" exists. We tested the premise that a single characteristic scale exists to understand speciesenvironment relationships within species by asking (a) what are the characteristic scales of species' relationships with environmental predictors, and (b) is withinspecies, cross-predictor consistency in characteristic scales a general phenomenon. Location: Nebraska, USA.

Time period: 2016.

Major taxa studied: Birds.

Methods: We used data from 86 species at $>500$ locations to build hierarchical $\mathrm{N}$ mixture models relating species abundance to land cover variables. By incorporating Bayesian latent indicator scale selection, we identified the spatial scales that best explain species-environment relationships with each land cover predictor. We quantified the extent of cross-predictor consistency in characteristic scales, and contrasted this to the expectation given a single species' characteristic scale.

Results: We found no evidence for a characteristic spatial scale explaining all abundance-environment relationships within species, rather we found substantial variation in scale-dependence across multiple environmental attributes. Furthermore, $33 \%$ of species displayed evidence of multiple important spatial scales within environmental attributes.

Major conclusions: Within species there is little evidence for a single characteristic scale of environmental relationships and considerable variation in species' scale dependencies. Because species may respond to multiple environmental attributes at different spatial scales, or single environmental attributes at multiple scales, we caution against any unoptimized single-scale studies. Our results demonstrate that until a framework is developed to predict the scales at which species respond to environmental characteristics, multi-scale investigations must be performed to identify and account for multi-scale dependencies. Natural selection acting on species' response to distinct environmental attributes, rather than natural selection acting on species' perception of spatial scales per se, may have shaped patterns of scale dependency and is an area ripe for investigation.
\end{abstract}


KEYWORDS

Bayesian latent indicator scale selection, characteristic scale, multi-scale, N-mixture, SCSS, spatial scale, species-environment relationship

\section{1 | INTRODUCTION}

Species abundance is a realization of multi-level habitat selection (sensu Johnson, 1980) as well as within-level, species-environment relationships, and is therefore expected to be shaped by ecological processes that manifest across various spatial extents (hereafter, spatial scales). Understanding the relevant scale(s) of species-environment relationships is a critical component of habitat and resource-selection studies, as well as species abundance and distribution modelling, which are increasingly viewed as powerful tools for informing conservation and management-driven questions (Fontaine et al., 2017; Stuber \& Fontaine, 2018) and contribute to the understanding of patterns of diversity, distribution, and evolution of scale dependency (Jarzyna \& Jetz, 2018).

The issue of scale has long been recognized in ecology (Johnson, 1980; Levin, 1992; Wiens, 1976, 1989) and the number of multi-scale studies (sensu McGarigal, Wan, Zeller, Timm, \& Cushman, 2016) actively aiming to align the spatial scales of observation with the spatial scales of underlying ecological processes are increasing. Haphazard approaches to assigning a scale at which to make biological inferences are gradually being replaced by evidence-based decisions (Wheatley \& Johnson, 2009); however, more than $75 \%$ of contemporary multiscale habitat or resource selection studies still fail to use empirical approaches to select the spatial scales from which to make inferences (based on a review of multi-scale habitat selection studies published between 2009 and 2014; McGarigal et al., 2016). Instead, the majority of investigations continue to make spatial scale selections based on convenience, lack of a priori expectations regarding the specific scale of effect, or unsubstantiated hypothesized relationships (e.g., a relationship between scale and species' average territory size) between species' response and scale, without examining whether the examined scale is appropriate. Even for the minority of studies using datadriven methods of scale selection, most are limited by convenience or convention to identifying a single best, or characteristic, spatial scale to understand all species-environment relationships (see Stuber, Gruber, \& Fontaine, 2017 for details), despite the awareness that alternative land cover types may provide biologically different ecological resources over unique spatial scales (Bergman et al., 2008; Hinsley, Bellamy, Newton, \& Sparks, 1995; Naugle, Higgins, Estey, Johnson, \& Nusser, 2000; Sandin \& Johnson, 2004). Particularly, collecting data or making inferences at inappropriate spatial scales is problematic when species-environment relationships are scale-dependent. When there is not a consistent pattern of species-environment response between scales, scientific inference may be strongly affected. The failure to consider various environmental attributes across the continuum of spatial scales likely to affect a species implicitly assumes that a characteristic selection scale (sensu Holland, Bert, \& Fahrig, 2004;
Wu \& Li, 2006) exists at the species level and can be extrapolated across environmental parameters impacting species' response.

The concept of a species' characteristic scale implies that for every species there is a single spatial scale at which individuals most strongly respond to environmental attributes (e.g., within the nesting substrate, versus within the home range), and that the spatial scale of the species-environment relationship is therefore an emergent property of a species. Although the initial introduction of a species' characteristic selection scale (SCSS) provided evidence to support a single best spatial scale in predicting space-use of a species, the focus of the study was on a single environmental characteristic (i.e., forest amount; Holland et al., 2004), and assumed a unimodal species response curve. Current single-scale studies may have extrapolated the idea of characteristic scales of ecological processes $(\mathrm{Wu} \& \mathrm{Li}$, 2006) to include species, or extrapolated conclusions of single-predictor studies (Holland et al., 2004) to include multiple environmental predictors, resulting in the propensity for multi-predictor single-scale investigations, and meta-analyses that average the scales of effect across predictors to a single species' characteristic scale. Most studies now consider the influence of multiple environmental attributes in shaping space use. However, when the "characteristic scale" of species-environment relationships is extrapolated from the evaluation of only a single environmental parameter, or the most important spatial scales of multiple environmental attributes are averaged within species (e.g., Martin, 2018; Thornton \& Fletcher, 2014), or if steps are not taken to identify relevant scales and only a single scale is assessed, investigators either explicitly or implicitly assume the existence of a single SCSS (e.g., generated through allometric scaling relationships; Jackson \& Fahrig, 2015; Thornton \& Fletcher, 2014). Constraining investigations to identifying a single possible characteristic scale or considering variation around a mean characteristic scale as noise without adequate supporting evidence may impede progress towards theories of scale dependency. Although evaluating a single environmental attribute is valid (ignoring omitted-variable bias), it is unclear based on existing research whether a SCSS based on a single environmental attribute can be generalized to other environmental attributes, or whether the average of SCSSs across multiple environmental attributes is an epiphenomenon without biological significance. The widespread use of single-scale models, and overarching goal of identifying a single "best" species' characteristic selection scale likely oversimplifies species-environment relationships, ignores the potential for multiple important spatial scales, and misrepresents uncertainty in spatial scale dependencies, potentially clouding our understanding of the ecology and evolution of scale dependency.

Despite the pervasiveness of single-scale studies in the literature, neither the notion that a single SCSS is pervasive across species, nor the possible mechanisms generating a single SCSS have been 
FIGURE 1 Five hundred and fortyfour avian point count survey sites were distributed across the state of Nebraska, USA, and monitored throughout the 2016 breeding season

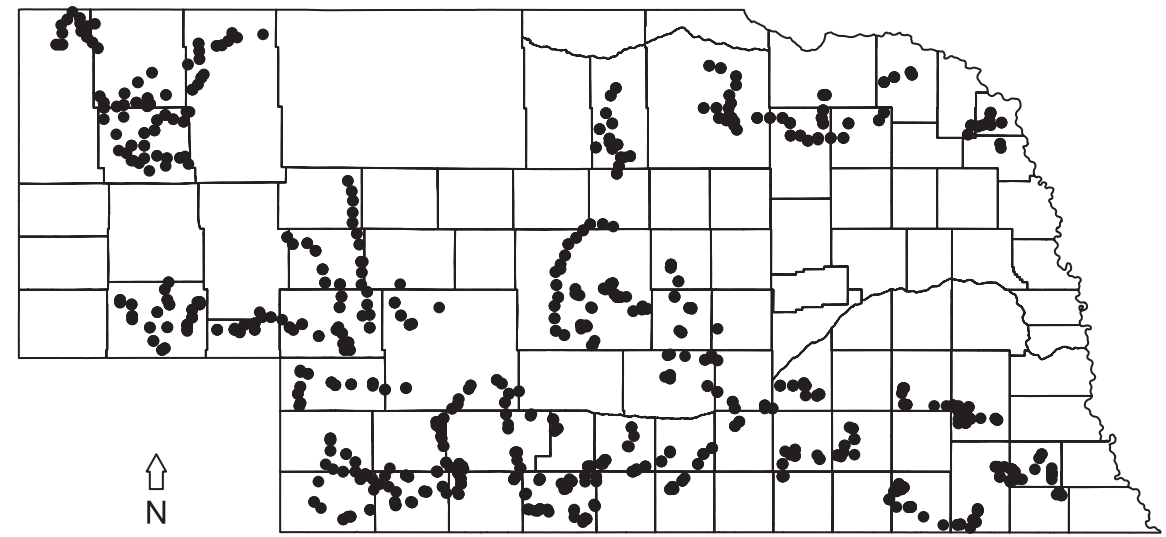

\begin{tabular}{lll}
\hline & $100 \quad 200 \mathrm{~km}$
\end{tabular} substantiated with empirical evidence (Stuber, Gruber, \& Fontaine, 2018), questioning the validity of single-scale studies, and increasingly, findings from meta-analyses of multi-scale studies. The concept of a single SCSS challenges much of what we understand about how natural selection acts upon species across multiple spatial scales, given that sources of natural selection are generally independent and manifest at different spatial and temporal scales (Addicott et al., 1987; Svensson \& Sinervo, 2004). An alternative to single SCSSs would be that species balance multiple sources of selective pressures and respond to each at the spatial scale that best predicts the specific source of natural selection (see Martin \& Fahrig, 2012 for examples of when a single SCSS would be expected; Miguet, Jackson, Jackson, Martin, \& Fahrig, 2016), resulting in multiple important scales for measuring species-environment relationships. Until recently, the notion of quantifying variation in SCSSs has been logistically challenging to test, but advances in computational approaches (e.g., Stuber et al., 2017) provide an opportunity to test support for the generality of an SCSS.

If characteristic scales of response are consistent across environmental relationships (i.e., the SCSS of Holland et al. 2004 can be extrapolated to multiple predictors), we should expect to find an unambiguous single "best" spatial scale to evaluate species-environment relationships for the majority of species considered. If, however, we find that the majority of species lack any systematic relationship with environmental attributes at a single spatial scale, or more importantly, species are responding to different environmental attributes at different spatial scales, then we must question the validity of uncritical extrapolation of a single SCSS to the species level, and indeed inferences made from unvalidated single-scale studies in general. In what we believe is the first comprehensive examination of the ability of a single SCSS to characterize a species' response, we propose to expand upon the notion of a species characteristic scale and demonstrate an approach for representing variation in species-environment relationships across spatial scales. We ask: (a) what are the characteristic scales that explain species-environment relationships when considering multiple environmental parameters, and (b) withinspecies, is a single best scale for species-environment relationships a general phenomenon across a taxonomic group of species.

\section{2 | METHODS}

\section{1 | Avian abundance surveys}

In the recent literature, birds represent c. $32 \%$ of multi-scale studies (with mammals representing $51 \%$ of multi-scale studies; McGarigal et al., 2016) and are well represented in species-environment relationship studies in general. We recorded the abundance of birds (Appendix 1) during May-July of 2016 across Nebraska, USA (Figure 1) using a replicated (maximum four) point count sampling method (Blondel, Ferry, \& Frochot, 1981; Buckland et al., 2001) to account for imperfect detection in subsequent statistical analyses (Williams, Nichols, \& Conroy, 2002). Survey site locations were selected based on a modified generalized random tessellation stratified sampling design to ensure that variation in the amounts of relevant land cover types was represented, and points were, on average, $600 \mathrm{~m}$ from their nearest neighbour. When weather conditions allowed (i.e., no fog, precipitation, or winds exceeding $20 \mathrm{~km} / \mathrm{h}$ ), point count surveys began $15 \mathrm{~min}$ before sunrise and ended at 10:00 hr, when aural detection rates are reliable across species (Hutto, Pletschet, \& Hendricks, 1986). During point count surveys, we recorded every individual seen or heard during a 3-min period within $500 \mathrm{~m}$ of the observer.

\section{2 | Land cover variables}

We investigated the relationships between avian species abundance and the proportions of six land cover types: row crop, Conservation Reserve Program (CRP) grassland (land historically in agricultural 
production but re-planted with native grass species), non-CRP grassland (largely remnant grassland used as working rangelands), small grain, woodland, and wetland. While the proportions of land cover types do not necessarily sum to 1 (i.e., other land cover types are also found in the landscape), the land cover types explored represent the majority of land use across Nebraska, and are expected to influence bird abundance at multiple spatial scales. We derived the proportion of each land cover type within multiple spatial scales $(0.5,1,2,3,4$, $5,10,15$ and $20 \mathrm{~km}$ radii) surrounding each survey point from a $30-\mathrm{m}$ resolution spatially explicit land cover product (Bishop, Barenberg, Volpe, \& Grosse, 2011; updated 2016). As there is no reliable method of predicting the spatial scales at which species respond to environmental characteristics, these scales represent candidate scales that we use in a data-driven approach for identifying scales of effect. The set of spatial scales ranged from the minimum point count sampling unit, to substantially larger than expected breeding territory sizes represented in our sample of species as suggested in the literature (Jackson \& Fahrig, 2012).

\section{3 | Statistical analysis}

As the base of our analysis we used a hierarchical $\mathrm{N}$-mixture model (Royle, 2004) that combines a Poisson process to model variation in true species abundance (modeled as a latent variable) with a conditional binomial process to model the detection of individuals. Our replicated survey design allowed us to separate the ecological process of interest, true abundance, from the observation process contributing to imperfect detection.

In the hierarchical N-mixture model we assumed a closed population for each site within year (Royle, 2004), and included the linear and quadratic effects of the proportion of row crop, CRP, grassland, small grain, woodland, and wetland as fixed effects, centered on the grand mean and scaled to $1 S D$, in the linear predictor for latent abundance. Our linear predictor for detection probability included date, time of survey and its quadratic effect, cloud cover, wind speed, and temperature, centered and scaled, and included observer (total five) as a random effect to account for among-individual differences in surveyor ability (Diefenbach, Brauning, \& Mattice, 2003; Kendall, Peterjohn, \& Sauer, 1996).

\section{4 | Quantifying within-species characteristic scales of multiple environmental predictor variables}

To address whether within species, there is a characteristic scale across multiple environmental predictors, for each species we performed a multi-scale, multi-predictor analysis. To incorporate multiple candidate spatial scales we used Bayesian latent indicator scale selection (BLISS; Stuber et al., 2017) estimated with Markov chain Monte Carlo (MCMC) sampling. BLISS is not sensitive to collinearity and enables complete flexibility in exploring candidate spatial scale model space such that all possible combinations of land cover types at different spatial scales are evaluated. Furthermore, BLISS outperforms other model selection techniques commonly used in multi-scale investigations and is robust to between- and withinpredictor autocorrelation, and sample size variation (Stuber et al., 2017). Furthermore, BLISS is one of only a few methods that has been validated through simulation studies to identify "true" scales of species-environment relationships across a range of sampling schemes, and environmental characteristics (see Stuber et al., 2017 for details). Briefly, the nine spatial scales represent candidate spatial scales that enter the base $\mathrm{N}$-mixture model as latent variables where each land cover predictor can appear in the model at any of the nine potential scales. Similar to typical MCMC sampling of coefficient estimates, the sampling procedure used in BLISS proposed a possible model at each iteration. A model included all land cover variables available in the study; however, at each iteration, each predictor could take a different spatial scale proportional to the predictor's probability, which allows predictor-specific identification of the most important spatial scales of the candidate set (see Stuber et al., 2017 for full details). All models were estimated with JAGS ("just another Gibbs sampler;" Plummer, 2003) via R (package "rjags"; Plummer 2014) using a 10,000 iteration burn-in period and based on 50,000 iterations. Models that initially failed to converge were run longer until they were assessed to converge (posterior distributions based on 50,000 iterations). For regression coefficients we used relatively weak priors, normally distributed around zero, and a discrete uniform distribution for all candidate scales. For each land cover variable and species, we designated the spatial scale with the highest posterior probability as the predictor characteristic selection scale (PCSS). We summarized the probabilities in PCSS for each species and each land cover variable to quantify uncertainty in selecting a single characteristic spatial scale, and visually assessed posterior distributions for evidence of multimodal patterns (e.g., a bimodal distribution might suggest two important scales of effect). We assessed a sample of our models ranging from low prevalence species to the highest prevalence for residual spatial autocorrelation left unexplained by model terms, and did not find evidence suggesting unexplained autocorrelation based on semi-variograms.

\section{5 | Quantifying generality of a single SCSS}

To determine whether characteristic scales across multiple predictors is a general phenomenon in birds, we quantified the variation in designated PCSSs among predictor variables by estimating a single linear mixed effects meta model (package "Ime4"; Bates, Mächler, Bolker, \& Walker, 2014) on the chosen PCSSs for each of the six land cover variables across all species including only the random effect of species (i.e., each species enters the model six times, once for each land cover predictor variable PCSS), in the following form: $\left(\right.$ scale $\left._{i}\right)=\beta_{0}+\gamma_{\text {species }_{i}}+\varepsilon_{i}$. There was one data point $i$ for each combination of species and land cover predictor, $\gamma_{\text {species }_{i}}$ represented a zero-mean normally distributed random intercept effect of species, and $\varepsilon_{i}$ represented an independent and normally distributed error term. We simulated the posterior distribution of the normal linear model using the sim function (package "arm"; Gelman et al., 2015) 
based on 5,000 draws. We estimated the among-species repeatability (also referred to as the intra-class correlation coefficient, ICC) of PCSS as the amount of among-species variance divided by the sum of among-species and residual variance (following Nakagawa \& Schielzeth, 2010) and we present residual variance as the withinspecies variance. We used the posterior modes to represent point estimates and present uncertainty based on $95 \%$ credible intervals around the estimates. We partition scale selection variance into its within- and among-species components to express the amount of variation that is consistent across repeated measures within species (e.g., here, repeated measures are based on multiple land cover variables), and assess the within-species correlation among repeated measurements (Nakagawa \& Schielzeth, 2010). A high intra-class correlation coefficient would indicate that species have consistently (e.g., across the six land cover variables) different PCSSs on average, which might arise for example, if larger species exhibited larger PCSSs than smaller species. A low intra-class correlation coefficient can represent either high within-species variation, or low amongspecies variation. High within-species variance would indicate that within-species, the PCSSs of different land cover variables take various values (e.g., an alternative to the SCSS concept). Low within-species variance would indicate that similar PCSSs are selected for all land cover variables within species, and represents the expectation of a single characteristic scale per species.

\section{3 | RESULTS}

We conducted surveys at 544 locations, with an average of 2.5 visits per survey location (SD: 1.1; min: 1). We observed 124 species, 88 of which we observed at more than two locations, the minimum required to fit a model. Of the 88 species, models did not converge for two species (house sparrow, Passer domesticus; red-winged blackbird, Agelaius phoeniceus). Prevalence of the 86 species in the analysed dataset ranged from a minimum of three survey sites with at least one detection (blue-gray gnatcatcher, Polioptila caerulea; greattailed grackle, Quiscalus mexicanus; Say's phoebe, Sayornis phoebe; and western wood-pewee, Contopus sordidulus) to a maximum of 465 having at least one detection (western meadowlark, Sturnella neglecta). Average, and minimum proportion of each land cover type were largely consistent between the minimum and maximum spatial scales considered, but the maximum proportion of land covers differed in CRP grassland, small grain, woodland, and wetland between the smallest and largest spatial scales (Table 1, Appendix 2).

\subsection{What are the characteristic scales that explain species-environment relationships when considering multiple environmental parameters?}

Designating the predictor-specific spatial scale with the highest posterior probability as the PCSS resulted in each of the nine spatial scales being selected as a PCSS for at least two species (maximum 21 species had the same PCSS in a single predictor; Figure 2).

The posterior probability in species' PCSS for each predictor ranged from .12 (i.e., the minimum probability to be designated as a PCSS) to 1.00 (i.e., no uncertainty in selection) (Appendix 1) with the average posterior probability ranging from .32 to .39 among predictor variables (SD: .22-.25 among predictors). Only two species (cliff swallow, Petrochelidon pyrrhonota: $\min .500 \mathrm{~m}$, max. 20 km; and lark bunting, Calamospiza melanocorys: $\min .500 \mathrm{~m}$, max. $20 \mathrm{~km}$ ) had at least a .5 posterior probability (i.e., an absolute majority) in PCSSs of all six land cover predictors. Nineteen percent of species exceeded a .50 probability for row crop, $27 \%$ for CRP grassland, $15 \%$ for grassland, $16 \%$ for small grain, $20 \%$ for woodland and $17 \%$ for wetland. Visual inspection of the posterior distributions of spatial scales revealed evidence of bimodal and multimodal distributions in at least one land cover variable in 28 species (Appendix 1; Figure 3).

\subsection{Within species, is a single best scale for species-environment relationships a general phenomenon across a taxonomic group of species?}

No single species had the same designated PCSS for all predictor variables, and the average difference among species' minimum and maximum designated PCSSs across predictors was $16 \mathrm{~km}$ (of both the full dataset and only considering species with prevalence $>.053$ ). Two species (2.3\%) had a maximum number of land cover predictors with the same designated PCSS exceeding three (five, blue grosbeak, Passerina caerulea; four, red-bellied woodpecker, Melanerpes carolinus; only red-bellied woodpecker in the high-prevalence dataset;
TABLE 1 Land cover characteristics (proportion of land cover type) within minimum (500-m radius) and maximum (20-km radius) spatial scales of 544 study sites across the state of Nebraska, USA

\begin{tabular}{|c|c|c|c|c|c|c|}
\hline \multirow[b]{2}{*}{ Land cover type } & \multicolumn{2}{|l|}{ Mean } & \multicolumn{2}{|c|}{ Minimum } & \multicolumn{2}{|c|}{ Maximum } \\
\hline & $500 \mathrm{~m}$ & $20 \mathrm{~km}$ & $500 \mathrm{~m}$ & $20 \mathrm{~km}$ & $500 \mathrm{~m}$ & $20 \mathrm{~km}$ \\
\hline Row crop & 0.28 & 0.34 & 0.00 & 0.00 & 0.96 & 0.85 \\
\hline CRP & 0.04 & 0.02 & 0.00 & 0.00 & 0.47 & 0.09 \\
\hline Grassland & 0.44 & 0.41 & 0.00 & 0.04 & 1.00 & 0.97 \\
\hline Small grain & 0.09 & 0.10 & 0.00 & 0.00 & 0.96 & 0.62 \\
\hline Woodland & 0.04 & 0.04 & 0.00 & 0.00 & 0.56 & 0.21 \\
\hline Wetland & 0.01 & 0.01 & 0.00 & 0.00 & 0.51 & 0.09 \\
\hline
\end{tabular}

Note: $\mathrm{CRP}=$ Conservation Reserve Program grassland. 

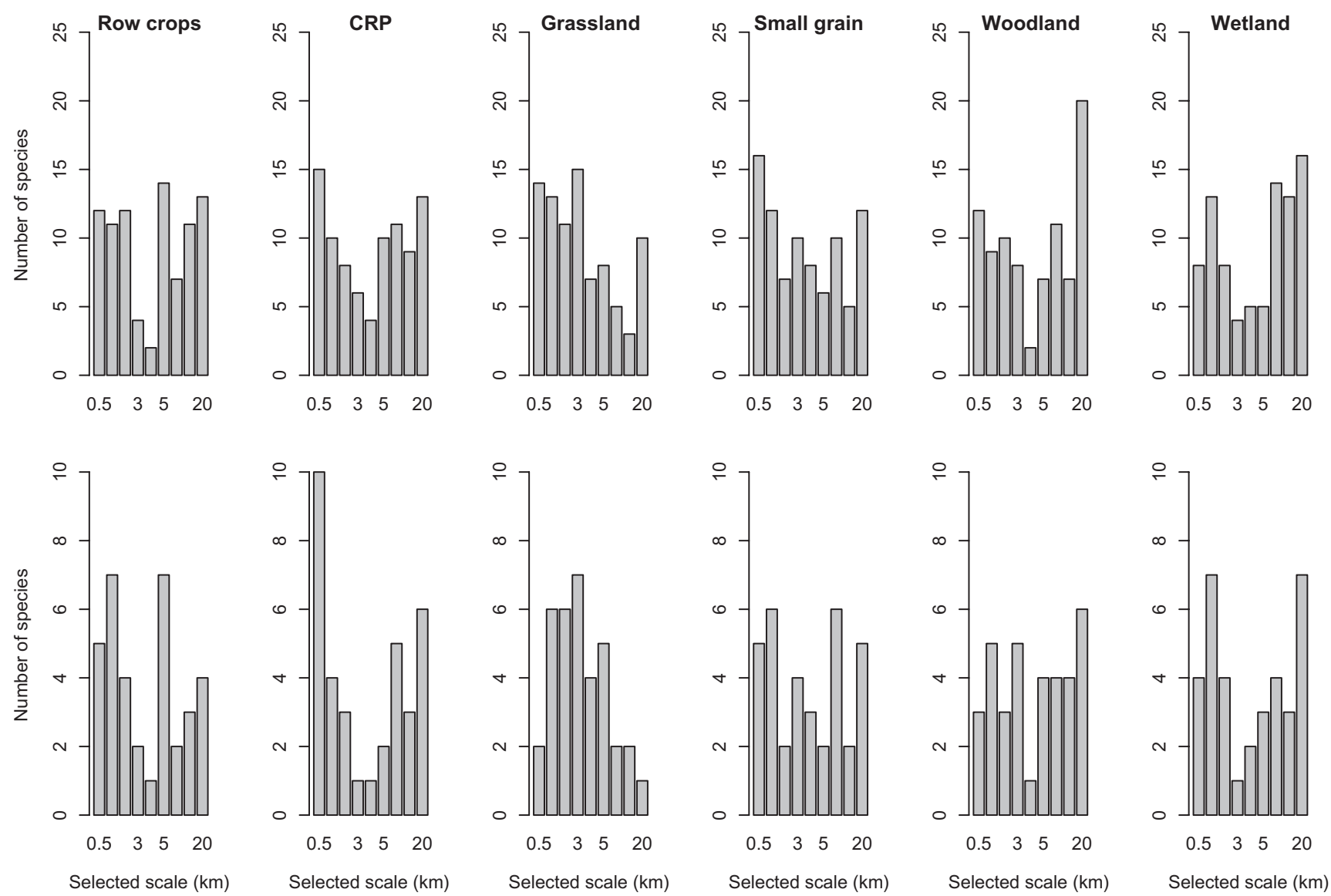

FIGURE 2 Number of species (top: of all 86 species; bottom: of 35 species observed at more than 29 study sites) for which each spatial scale was selected as a species' characteristic selection scale (SCSS). SCSS was defined as the spatial scale containing the greatest posterior probability based on Bayesian latent indicator scale selection considering nine candidate spatial scales and six different land cover predictors. CRP $=$ Conservation Reserve Program grassland

$2.8 \%$ ), 17 species (20\%) had a maximum of three (five species in the high-prevalence dataset; $14 \%$ ) and 56 species (65\%) had a maximum of two (25 species in the high-prevalence dataset; 71\%) land cover predictors with PCSSs designated at the same scale.

We found high residual variance in our linear mixed-effects meta-model, which indicated that PCSS is not consistent within species across predictor variables and all species considered could display PCSSs across the full range of scales considered; high residual variance remains even if we only consider PCSSs with at least .5 posterior probability in this model (100 observations from 45 species; data not shown). We did not detect among-species repeatability in the PCSS of multiple predictors, indicating that species did not differ in their average scale of response [linear mixed-model estimated among-species variance: 152,215 (95\% credible interval (Cl) 105,023 204,830); residual variance: $49,165,740(95 \% \mathrm{Cl}$ $44,837,50057,163,880)$; repeatability $(R)=.003]$. If we restrict our meta-model to consider only species with a prevalence of .05 and greater (e.g., observed at 30 or more survey locations; 35 species) residual variance remains similarly high $[46,309,820(95 \% \mathrm{Cl}$ $38,426,720$ 55,726,140)]. Both among-species variance and subsequently repeatability are indistinguishable from zero. The same pattern holds when censoring the data to prevalence greater than
.11 (e.g., observed at 60 or more survey locations; 23 species). For comparison, if each species had the same scale selected for each land cover predictor (e.g., low within-species variation, expectation of a SCSS per species) we would expect very low residual variance, and very high among-species variance. Simulating these data, for each species, assigning the mean selected scale to each of the six land cover predictors results in both high among-species variance $(8,583,527 ; 95 \% \mathrm{Cl} 8,577,6678,588,796)$ and repeatability $(.9995 \%$ $\mathrm{Cl} .98$.999) and within-species variance five orders of magnitude smaller than the actual data $(116 ; 95 \% \mathrm{Cl} 103,132)$.

The posterior probabilities in species' PCSSs were positively correlated with species' prevalence in row crop $(r=.40,95 \%$ confidence interval .21, .56), CRP ( $r=.22$, 95\% confidence interval .005, .41 ), grassland ( $r=.32,95 \%$ confidence interval 0.11, 0.50), woodland ( $r=.25,95 \%$ confidence interval .04, .44), and wetland land cover variables ( $r=.29,95 \%$ confidence interval .09, .48). There was moderate evidence for a correlation between species prevalence and probability in the PCSS of small grain land cover $(r=0.17,95 \%$ confidence interval -.05, .36). A positive correlation between prevalence and posterior probability of the PCSS indicates that there is less certainty associated with a single best scale the rarer a species is in the data. 
FIGURE 3 Representative sample (from 28 possible species) of posterior probability plots indicating evidence of multimodal species-scale relationships within land cover types. Posterior probabilities of nine candidate spatial scales and six different land cover predictors were estimated with Bayesian latent indicator scale selection
Bobolink

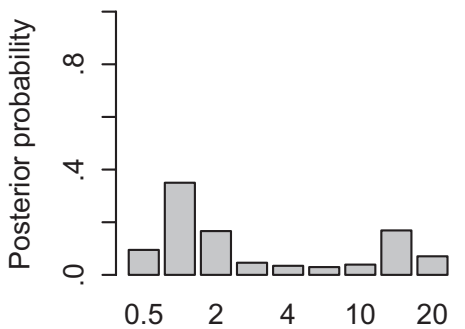

Spatial scale $(\mathrm{km})$ grassland

Grasshopper sparrow

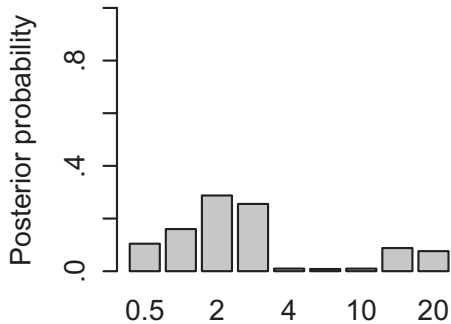

Spatial scale $(\mathrm{km})$ woodland

Upland sandpiper

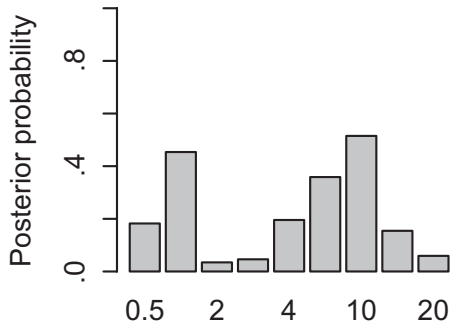

Spatial scale $(\mathrm{km})$ small grain
Dickcissel

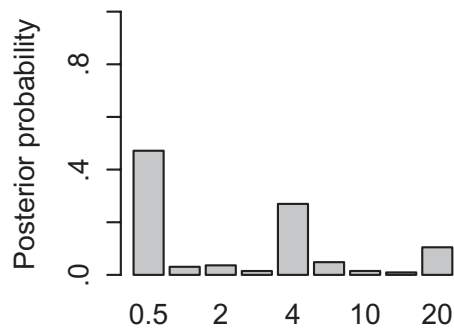

Spatial scale $(\mathrm{km})$ wetland

Ring-necked pheasant

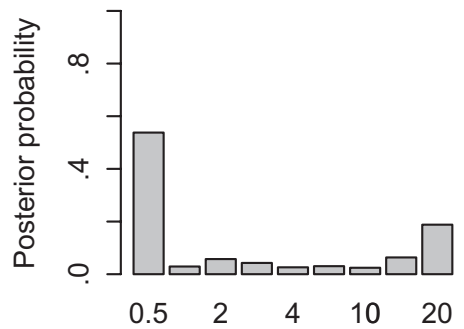

Spatial scale $(\mathrm{km})$ wetland

Yellow-headed blackbird

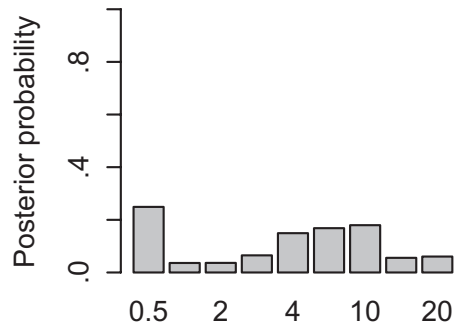

Spatial scale $(\mathrm{km})$ row crops

\section{4 | DISCUSSION}

We demonstrate a framework for quantifying the characteristic scales of species-environment relationships across multiple environmental predictors. Our results provide strong evidence that a single SCSS is not widespread across species-environment relationships, which casts doubt upon ubiquitous single-scale studies. Although it is well established that different species may respond to the same environmental attributes at different spatial scales, we provide evidence of substantial intraspecific variation in characteristic scales across different environmental attributes suggesting that species have many characteristic scales of response across multiple environmental parameters.

Why should species respond to different environmental attributes at independent spatial scales rather than all environmental attributes at a single important spatial scale? Our findings are perhaps not surprising if we consider that the scaling of biological responses is a product of the scaling of underlying ecological processes shaping the biological response. For example, the abundance of individuals breeding within an area is shaped in part by interactions between ecological rates of immigration, emigration, reproduction and mortality, which are in turn shaped by abiotic and biotic interactions that manifest at various spatial scales. Studies of scale dependency within these hierarchical processes, however, are scarce. Additionally, we might expect multiple scales of response particularly for species with spatially independent resource requirements (i.e., resource or landscape complementarity, Dunning, Danielson, \& Pulliam, 1992; Tilman, 1982). When considering foraging and breeding, for example, the interaction between environmental composition and configuration in the ecological neighbourhood might manifest as spatially distinct characteristic scales representing foraging versus breeding habitat. Furthermore, we could expect intraspecific variation in the characteristic scales of various environmental attributes if the ecological processes shaping various environmental patterns (e.g., disturbance, nutrient cycling and topography) operate at distinct scales (Holling, 1985; Legendre, 1993). Our findings challenge the validity of the current general practice of conducting single-scale analyses, which implicitly assumes that species respond to environmental attributes within a single particular spatial scale (i.e., the extrapolated SCSS), for example through metabolic or body size 
scaling relationships, and perceptual ability (Fisher, Anholt, \& Volpe, 2011; Holland, Fahrig, \& Cappuccino, 2005; Jackson \& Fahrig, 2012; Thornton \& Fletcher, 2014; but see Stuber et al., 2018).

Although the spatial scales of underlying ecological processes may lead to characteristic scales of environmental patterns, it is the combination of a species' perceptual ability and the spatial scale of species-environment interactions that ultimately defines how a species responds to their environment. Indeed, if the fundamental spatial scale characterizing environmental variation alone determined an SCSS, we might not expect substantial interspecific variation in PCSSs of environmental attributes. Mismatches between the fundamental scales of ecological processes and the scale at which a species perceives or interacts with the environment likely lead to discrepancies in predicting an SCSS. For a given environmental characteristic, multiple species might have different characteristic scales based on traits such as territory size, or annual movement distances, which may reflect the scale at which individuals of a species evaluate the landscape during habitat selection (but see Stuber et al., 2018). For example, the spatial scale of prospecting behaviour for breeding habitat selection varies among species, is likely related to breeding density (Doligez, Part, \& Danchin, 2004) and may be indicative of the PCSS of predictors of abundance.

Within species, the PCSSs of environmental predictors could take values across a full range of spatial scales. We can either regard intraspecific variation in PCSSs as error around a possibly adaptive species mean (i.e., a single SCSS per species), or as variation in trait expression that is either adaptive, reflecting natural selection pressures shaping different species-environment relationships, or maladaptive, for example with spatial variation in ecological traps. Determining the intraspecific repeatability of PCSSs, whether, for example, a PCSS is consistent across multiple years or distinct geographic areas, would provide information on the degree of intraspecific plasticity in spatial relationships. Uncovering the extent of intraspecific plasticity would allow us to begin to identify sources of variation in responses to environmental features. Although we focus on spatial scale, it is important to note that temporal scale, and indeed the resolution component of spatial and temporal scale, are also important considerations for similar ecological questions that will contribute to a complete perspective of scale dependency in space use (Urban, Oneill, \& Shugart, 1987; Wiens, 1989).

Intraspecific designations of PCSSs resulted in both uni- and multimodal probability distributions of candidate spatial scales. Because the distributions for the PCSSs we estimated correspond to a single year of data collection assumed to represent a closed population, any multimodality reflects a snapshot of population structure and not temporal variability. Multimodal PCSS patterns are perhaps the most striking evidence against the notion of a single SCSS. While characterizing a single SCSS for a species may be an aim, even the initial investigation of species' characteristic scales presented evidence of bimodal patterns, and general ambiguity of single-scale selection with statistically indistinguishable peaks and runs in important spatial scales (Holland et al., 2004). Unimodal species response curves are typically assumed in species distribution modelling where the main assumption is a single fitness optimum on an environmental gradient that reflects the highest probability of occurrence, or greatest abundance (Austin, 2002). However, similar to multiple peaks on a fitness landscape, multimodal patterns can be expected when multiple phenotypes have isolated local fitness peaks (Martin \& Wainwright, 2013; Whitlock, Phillips, Moore, \& Tonsor, 1995). In the case of PCSSs, if populations of the same species differ in the spatial scale predicting the abundance-habitat relationship, for example across an environmental or population density gradient perhaps representing local adaptation, it could manifest as multiple probability peaks in a PCSS designation, or contribute generally to the substantial within-species variation in PCSSs. Alternatively, multiple probability peaks could also indicate multiple underlying ecological processes shaping PCSSs (Miller \& Hanham, 2011). If a single environmental characteristic acts as a cue for multiple resources or processes, such as reflecting breeding habitat at small scales and predation risk at larger scales simultaneously, we would expect two PCSSs with high probability.

Closer inspection of a subset of species (dickcissel, Spiza americana; eastern meadowlark, Sturnella magna; field sparrow, Spizella pusilla; grasshopper sparrow, Ammodramus savannarum; lark sparrow, Chondestes grammacus; northern bobwhite, Colinus virginianus; ring-necked pheasant, Phasianus colchicus; data not shown) revealed that coefficient estimates of land cover predictors change in small increments between neighbouring spatial scales, in some instances eventually changing sign. Within the spatial scales investigated here, we do not see evidence of "transition zones" with unpredictable estimates (e.g., not systematically increasing or decreasing) between scale domains (Wiens, 1989). Small changes in species-environment relationships across spatial scales suggest that presumably different spatial scales are within the same "scale domain" (Wiens, 1989), or that scale dependency of species-environment relationships is continuous - every change in scale reflects a change in the relationship. For cases of continuous scale dependency, the consequences of selecting or collecting data at an inappropriate spatial scale are exacerbated if the sign of the relationship changes among scales, because there is likely not a consistent pattern of response among scales. When estimates are stable, or change monotonically, errors of scale selection are less important as the relationship is either scaleinsensitive, or predictable within the scale domain. Alternatively, our inability to detect transition zones could reflect the range of spatial scales we considered. If the outcomes of natural selection are weakly spatially dependent, transitions could be abrupt, but occur within the intervals between the spatial scales we considered. Whether representing a continuum of selective pressures or weak natural selection, our failure to find distinct transitions between the spatial scales is further evidence that the SCSS concept may be overly simplistic.

However, a flat posterior distribution across a range of spatial scales, representing scale independence, can be interpreted as all spatial scales being either equally good or equally bad at predicting a biological response. Decision rules would need to be carefully considered to establish whether a particular environmental characteristic appears scale independent because there is no ecological 
relationship to detect (e.g., coefficient effect size biologically zero), or because all measured scales are equally important (e.g., coefficient effect size biologically non-zero). Indeed, uncertainty in spatial scale selection increases as coefficient effect sizes decrease (Stuber et al., 2017). Nevertheless, our conclusions hold even if we restrict our analysis to PCSS designations with relatively low uncertainty.

Although our data question the validity of extrapolating the SCSS concept to the whole-species level, there is value in continuing to conduct scale-explicit studies. Species-environment relationships measured at one spatial scale often do not predict relationships at another spatial scale. Inferences made from models using information from non-representative spatial scales of species-environment relationships are likely to generate inappropriate conclusions (Shirk, Raphael \& Cushman et al., 2014; Thompson \& McGarigal, 2002; Wheatley, 2010), a problem that is further exacerbated when species are rare. Not surprisingly, we found prevalence-dependence of uncertainty in designating PCSSs. Adequately modelling rare species is a ubiquitous problem in ecology (Cunningham \& Lindenmayer, 2005; Engler, Guisan, \& Rechsteiner, 2004; Sileshi, Hailu, \& Nyadzi, 2009; Welsh, Cunningham, Donnelly, \& Lindenmayer, 1996), and there is no substitute for additional observations when identifying multiscale species-environment relationships. Indeed, while we collected a relatively large dataset (> 500 study sites, surveyed in replicate), species-targeted study designs to guarantee an appropriate presence-absence ratio appears necessary to make strong inferences in some cases. Species that had an absolute majority of posterior probability (i.e., .50) in a PCSS had an average prevalence of .16, whereas species with less than .50 posterior probability had significantly lower prevalence $(.09 ; p<.05)$. Furthermore, while our study aims to identify the spatial scales of species-environment relationships, and we employ methods demonstrated to be highly accurate at this task with the study design we developed, caution should be used if inference about population size is an additional interest from this form of hierarchical model. Indeed, studies have highlighted that under certain conditions violations of $\mathrm{N}$-mixture model assumptions can lead to biased estimates of population size (Knape et al., 2018; Link, Schofield, Barker, \& Sauer, 2018), and non-identifiability of abundance and detection parameters if absolute rather than relative abundance estimates are necessary (Barker, Schofield, Link, \& Sauer, 2018; Kéry, 2018).

Despite long-standing interest in the spatial scale of ecological processes and patterns, there is a surprising paucity of multi-scale research and multi-scale optimization in organism-environment relationship studies (McGarigal et al., 2016). The notion of a general "characteristic scale" of species' responses coupled with a limited range of investigated spatial scales (Heisler, Poulin, \& Somers, 2017), and a lack of error propagation have contributed to an overstated sense of certainty in the identification of relevant spatial scales at which to conduct research and consider ecological frameworks for predicting the spatial scales of species-environment relationships. Ignoring the extent of uncertainty in selecting important spatial scales can obscure relationships in subsequent analyses, for example when investigating mechanistic relationships between PCSS and longevity of habitat, or species' dispersal ability. Until we appreciate the extent to which the spatial scales of environmental relationships vary both among and within species, a predictive framework for determining the spatial scales of species-environment relationships will remain elusive. New analytical techniques, and sources of environmental data will enable researchers to move away from the oversimplified assumption of a single SCSS to gain more ecologically relevant insights into the multi-scale nature of species-environment relationships, and the evolution of scale dependency in these relationships. Incorporating biological understanding of multi-scale species-environment relationships across space and time will shed light on the ecological sources of variation in important spatial scales that will likely lead to the generation of new hypotheses to explain among- and within-species patterns, providing insight into the generation and maintenance of scale dependency in species-environment relationships.

\section{ACKNOWLEDGMENTS}

Funding for this project was received from Federal Aid in Wildlife Restoration project W98-R, administered by the Nebraska Game and Parks Commission. We would like to thank Chelsea Forehead, Caitlyn Gillespie, Anthony Jenniges, Amanda Lipinski and Lindsey Messinger for assistance with field data collection, and Annie Madsen for assistance in conducting the literature review. We gratefully acknowledge Nick Isaac and 2 anonymous reviewers for critical comments that have improved earlier versions of the manuscript. Any use of trade, firm, or product names is for descriptive purposes only and does not imply endorsement by the U.S. Government. The Nebraska Cooperative Fish and Wildlife Research Unit is supported by a cooperative agreement among the U.S. Geological Survey, the Nebraska Game and Parks Commission, the University of Nebraska, the U.S. Fish and Wildlife Service, and the Wildlife Management Institute. The authors declare no conflicts of interest.

\section{DATA AVAILABILITY STATEMENT}

The data and analysis code supporting the findings of this study are available in Dryad (https://doi.org/10.5061/dryad.31ks8p5).

\section{ORCID}

Erica F. Stuber (iD https://orcid.org/0000-0002-2687-6874

\section{REFERENCES}

Addicott, J. F., Aho, J. M., Antolin, M. F., Padilla, D. K., Richardson, J. S., \& Soluk, D. A. (1987). Ecological neighbourhoods-Scaling environmental patterns. Oikos, 49, 340-346. https://doi.org/10.2307/3565770

Austin, M. (2002). Spatial prediction of species distribution: An interface between ecological theory and statistical modelling. Ecological Modelling, 157, 101-118. https://doi.org/10.1016/S0304-3800(02)00205-3

Barker, R. J., Schofield, M. R., Link, W. A., \& Sauer, J. R. (2018). On the reliability of $\mathrm{N}$-mixture models for count data. Biometrics, 74, 369-377. https://doi.org/10.1111/biom.12734 
Bates, D., Mächler, M., Bolker, B., \& Walker, S. (2014). Fitting linear mixed-effects models using Ime4. arXiv preprint arXiv:1406.5823.

Bergman, K. O., Ask, L., Askling, J., Ignell, H., Wahlman, H., \& Milberg, P. (2008). Importance of boreal grasslands in Sweden for butterfly diversity and effects of local and landscape habitat factors. Biodiversity and Conservation, 17, 139-153. https://doi.org/10.1007/ s10531-007-9235-x

Bishop, A., Barenberg, A., Volpe, N., \& Grosse, R. (2011). Nebraska land cover development. Rainwater Basin Joint Venture Report. Grand Island, NE.

Blondel, J., Ferry, C., \& Frochot, B. (1981). Point counts with unlimited distance. Studies in Avian Biology, 6, 414-420.

Buckland, S. T., Anderson, D. R., Burnham, K. P., Laake, J. L., Borchers, D. L., \& Thomas, L. (2001). Introduction to distance sampling estimating abundance of biological populations. New York, NY: Oxford University Press.

Cunningham, R. B., \& Lindenmayer, D. B. (2005). Modeling count data of rare species: Some statistical issues. Ecology, 86, 1135-1142. https:// doi.org/10.1890/04-0589

Diefenbach, D. R., Brauning, D. W., \& Mattice, J. A. (2003). Variability in grassland bird counts related to observer differences and species detection rates. The Auk, 120, 1168-1179. https://doi. org/10.1642/0004-8038(2003)120[1168:VIGBCR]2.0.CO;2

Doligez, B., Part, T., \& Danchin, E. (2004). Prospecting in the collared flycatcher: Gathering public information for future breeding habitat selection? Animal Behaviour, 67, 457-466. https://doi.org/10.1016/j. anbehav.2003.03.010

Dunning, J. B., Danielson, B. J., \& Pulliam, H. R. (1992). Ecological processes that affect populations in complex landscapes. Oikos, 169175. https://doi.org/10.2307/3544901

Engler, R., Guisan, A., \& Rechsteiner, L. (2004). An improved approach for predicting the distribution of rare and endangered species from occurrence and pseudo-absence data. Journal of Applied Ecology, 41, 263-274. https://doi.org/10.1111/j.0021-8901.2004.00881.x

Fisher, J. T., Anholt, B., \& Volpe, J. P. (2011). Body mass explains characteristic scales of habitat selection in terrestrial mammals. Ecology and Evolution, 1, 517-528. https://doi.org/10.1002/ece3.45

Fontaine, J. J., Jorgensen, C. F., Stuber, E. F., Gruber, L. F., Bishop, A. A., Lusk, J. J., ... Decker, K. L. (2017). Species distributions models in wildlife planning: Agricultural policy and wildlife management in the great plains. Wildlife Society Bulletin, 41, 194-204. https://doi. org/10.1002/wsb.763

Gelman, A., Su, Y.-S., Yajima, M., Hill, J., Pittau, M. G., Jouni, K., Zheng T., Dorie, V. (2015). Arm: Data analysis using regression and multilevel/ hierarchical models: R package. Version 1.6. Retrieved from: https:// cran.r-project.org/web/packages/arm/index.html

Heisler, L. M., Poulin, R. G., \& Somers, C. M. (2017). Stop using dichotomous terms to reference observations of scale-dependent habitat selection. Landscape Ecology, 32, 1531-1542. https://doi.org/10.1007/ s10980-017-0543-6

Hinsley, S. A., Bellamy, P. E., Newton, I., \& Sparks, T. H. (1995). Habitat and landscape factors influencing the presence of individual breeding bird species in woodland fragments. Journal of Avian Biology, 26, 94-104. https://doi.org/10.2307/3677057

Holland, J. D., Bert, D. G., \& Fahrig, L. (2004). Determining the spatial scale of species' response to habitat. BioScience, 54, 227-233. https ://doi.org/10.1641/0006-3568(2004)054[0227:DTSSOS]2.0.CO;2

Holland, J. D., Fahrig, L., \& Cappuccino, N. (2005). Body size affects the spatial scale of habitat-beetle interactions. Oikos, 110, 101-108. https://doi.org/10.1111/j.0030-1299.2005.13638.x

Holling, C. (1985). Resilience of ecosystems: local surprise and global change. In J. G. Roederer, \& T. F. Malone (Eds.), Global Change (pp. 228-269). Cambridge, UK: Cambridge University Press.

Hutto, R. L., Pletschet, S. M., \& Hendricks, P. (1986). A fixed-radius point count method for nonbreeding and breeding-season use. The Auk, 103, 593-602.
Jackson, H. B., \& Fahrig, L. (2012). What size is a biologically relevant landscape? Landscape Ecology, 27, 929-941. https://doi.org/10.1007/ s10980-012-9757-9

Jackson, H. B., \& Fahrig, L. (2015). Are ecologists conducting research at the optimal scale? Global Ecology and Biogeography, 24, 52-63. https ://doi.org/10.1111/geb.12233

Jarzyna, M. A., \& Jetz, W. (2018). Taxonomic and functional diversity change is scale dependent. Nature Communications, 9, 2565. https:// doi.org/10.1038/s41467-018-04889-z

Johnson, D. H. (1980). The comparison of usage and availability measurements for evaluating resource preference. Ecology, 61, 65-71. https ://doi.org/10.2307/1937156

Kendall, W. L., Peterjohn, B. G., \& Sauer, J. R. (1996). First-time observer effects in the North American Breeding Bird Survey. The Auk, 113, 823-829. https://doi.org/10.2307/4088860

Kéry, M. (2018). Identifiability in N-mixture models: A large-scale screening test with bird data. Ecology, 99, 281-288.

Knape, J., Arlt, D., Barraquand, F., Berg, Å., Chevalier, M., Pärt, T., ... Żmihorski, M. (2018). Sensitivity of binomial N-mixture models to overdispersion: The importance of assessing model fit. Methods in Ecology and Evolution, 9, 2102-2114. https://doi. org/10.1111/2041-210X.13062

Legendre, P. (1993). Spatial autocorrelation-Trouble or new paradigm. Ecology, 74, 1659-1673. https://doi.org/10.2307/1939924

Levin, S. A. (1992). The problem of pattern and scale in ecology. Ecology, 73, 1943-1967.

Link, W. A., Schofield, M. R., Barker, R. J., \& Sauer, J. R. (2018). On the robustness of $\mathrm{N}$-mixture models. Ecology, 99, 1547-1551. https://doi. org/10.1002/ecy.2362

Martin, A. E. (2018). The spatial scale of a species' response to the landscape context depends on which biological response you measure. Current Landscape Ecology Reports, 3, 23-33. https://doi. org/10.1007/s40823-018-0030-z

Martin, A. E., \& Fahrig, L. (2012). Measuring and selecting scales of effect for landscape predictors in species-habitat models. Ecological Applications, 22, 2277-2292. https://doi.org/10.1890/11-2224.1

Martin, C. H., \& Wainwright, P. C. (2013). Multiple fitness peaks on the adaptive landscape drive adaptive radiation in the wild. Science, 339, 208-211. https://doi.org/10.1126/science.1227710

McGarigal, K., Wan, H. Y., Zeller, K. A., Timm, B. C., \& Cushman, S. A (2016). Multi-scale habitat selection modeling: A review and outlook. Landscape Ecology, 31, 1161-1175. https://doi.org/10.1007/ s10980-016-0374-x

Miguet, P., Jackson, H. B., Jackson, N. D., Martin, A. E., \& Fahrig, L. (2016). What determines the spatial extent of landscape effects on species? Landscape Ecology, 31, 1177-1194. https://doi.org/10.1007/ s10980-015-0314-1

Miller, J. A., \& Hanham, R. Q. (2011). Spatial nonstationarity and the scale of species-environment relationships in the Mojave Desert, California, USA. International Journal of Geographical Information Science, 25, 423-438. https://doi.org/10.1080/13658816.2010.518147

Nakagawa, S., \& Schielzeth, H. (2010). Repeatability for Gaussian and non-Gaussian data: A practical guide for biologists. Biological Reviews of the Cambridge Philosophical Society, 85, 935-956. https://doi. org/10.1111/j.1469-185X.2010.00141.x

Naugle, D. E., Higgins, K. F., Estey, M. E., Johnson, R. R., \& Nusser, S. M. (2000). Local and landscape-level factors influencing black tern habitat suitability. The Journal of Wildlife Management, 64, 253-260. https ://doi.org/10.2307/3802997

Plummer, M. (2003). JAGS: A program for analysis of Bayesian graphical models using Gibbs sampling. Proceedings of the 3rd international workshop on distributed statistical computing, 124, 125.

Plummer, M. (2014). Rjags: Bayesian graphical models using MCMC. $R$ package version 3-10. Statistical software. Retrieved from https:// CRAN.R-project.org/package=rjags 
Royle, J. A. (2004). N-mixture models for estimating population size from spatially replicated counts. Biometrics, 60, 108-115.

Sandin, L., \& Johnson, R. K. (2004). Local, landscape and regional factors structuring benthic macroinvertebrate assemblages in Swedish streams. Landscape Ecology, 19, 501-514. https://doi.org/10.1023/ B:LAND.0000036116.44231.1c

Shirk, A. J., Raphael, M. G., \& Cushman, S. A. (2014). Spatiotemporal variation in resource selection: insights from the American marten (Martes americana). Ecological Applications, 24, 1434-1444.

Sileshi, G., Hailu, G., \& Nyadzi, G. I. (2009). Traditional occupancy-abundance models are inadequate for zero-inflated ecological count data. Ecological Modelling, 220, 1764-1775. https://doi.org/10.1016/j. ecolmodel.2009.03.024

Stuber, E. F., \& Fontaine, J. J. (2018). Ecological neighborhoods as a framework for umbrella species selection. Biological Conservation, 223, 112-119. https://doi.org/10.1016/j.biocon.2018.04.026

Stuber, E. F., Gruber, L. F., \& Fontaine, J. J. (2017). A Bayesian method for assessing multi-scale species-habitat relationships. Landscape Ecology, 32, 2365-2381. https://doi.org/10.1007/s10980-017-0575-y

Stuber, E. F., Gruber, L. F., \& Fontaine, J. J. (2018). Predicting species-habitat relationships: Does body size matter? Landscape Ecology, 33(7), 1049-1060. https://doi.org/10.1007/s10980-018-0648-6

Svensson, E. I., \& Sinervo, B. (2004). Spatial scale and temporal component of selection in side-blotched lizards. The American Naturalist, 163, 726-734. https://doi.org/10.1086/383592

Thompson, C. M., \& McGarigal, K. (2002). The influence of research scale on bald eagle habitat selection along the lower Hudson RiverNew York (USA). Landscape Ecology, 17, 569-586.

Thornton, D. H., \& Fletcher, R. J. (2014). Body size and spatial scales in avian response to landscapes: A meta-analysis. Ecography, 37, 454-463.

Tilman, D. (1982). Resource competition and community structure. Princeton, NJ: Princeton University Press.

Urban, D. L., Oneill, R. V., \& Shugart, H. H. (1987). Landscape ecology: A hierarchical perspective can help scientists understand spatial patterns. BioScience, 37, 119-127. https://doi.org/10.2307/1310366

Welsh, A. H., Cunningham, R. B., Donnelly, C. F., \& Lindenmayer, D. B. (1996). Modelling the abundance of rare species: Statistical models for counts with extra zeros. Ecological Modelling, 88, 297-308. https:// doi.org/10.1016/0304-3800(95)00113-1
Wheatley, M. (2010). Domains of scale in forest-landscape metrics: Implications for species-habitat modeling. Acta Oecologica, 36, 259-267.

Wheatley, M., \& Johnson, C. (2009). Factors limiting our understanding of ecological scale. Ecological Complexity, 6, 150-159. https://doi. org/10.1016/j.ecocom.2008.10.011

Whitlock, M. C., Phillips, P. C., Moore, F. B. G., \& Tonsor, S. J. (1995). Multiple fitness peaks and epistasis. Annual Review of Ecology and Systematics, 26, 601-629. https://doi.org/10.1146/annur ev.es.26.110195.003125

Wiens, J. A. (1976). Population responses to patchy environments. Annual Review of Ecology and Systematics, 7, 81-120. https://doi. org/10.1146/annurev.es.07.110176.000501

Wiens, J. A. (1989). Spatial scaling in ecology. Functional Ecology, 3, 385397. https://doi.org/10.2307/2389612

Williams, B. K., Nichols, J. D., \& Conroy, M. J. (2002). Analysis and management of animal populations. San Diego, CA: Academic Press.

Wu, J., \& Li, H. (2006). Concepts of scale and scaling. In J. Wu, K. B. Jones, H. Li, \& O. L. Loucks (Eds.), Scaling and uncertainty analysis in ecology: Methods and applications (pp. 3-15). Dordrecht: Springer.

\section{BIOSKETCHES}

Erica Stuber is a quantitative ecologist interested in linkages between ecological processes across spatial and organizational scales.

Joseph Fontaine is an evolutionary ecologist studying how novel ecological conditions driven by anthropogenic change influence phenotypic expression and community dynamics.

How to cite this article: Stuber EF, Fontaine JJ. How characteristic is the species characteristic selection scale? Global Ecol Biogeogr. 2019;28:1839-1854. https://doi.org/10.1111/ geb.12998 


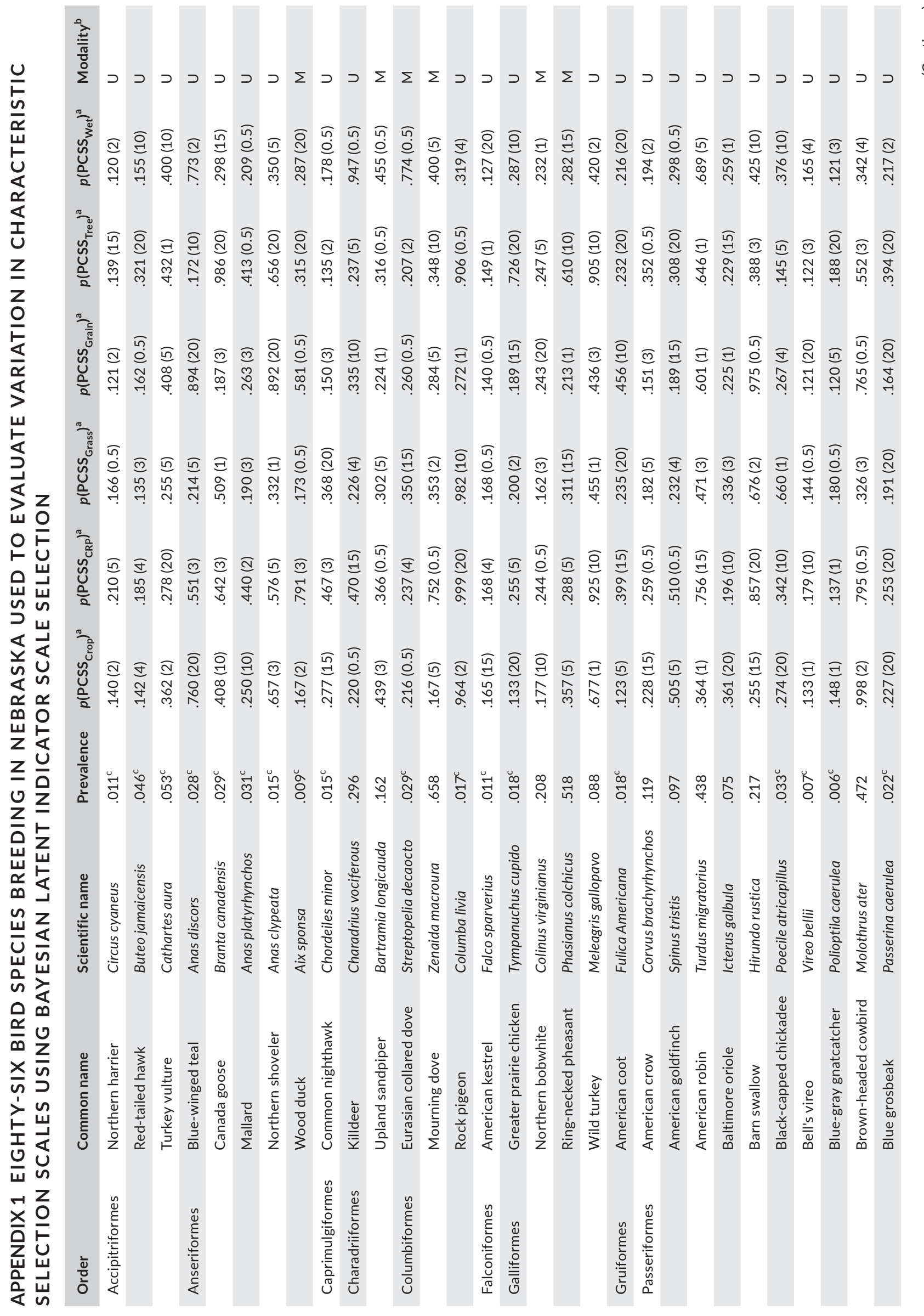


$\frac{2}{\frac{2}{\pi}}$

$\Sigma \Sigma \supset \Sigma \supset \supset \Sigma \supset$

$\Sigma \supset \Sigma \supset \Sigma \Sigma \Sigma \Sigma \supset \Sigma \supset \supset$

$\supset \Sigma$

$\supset \supset \Sigma \Sigma \supset \supset$

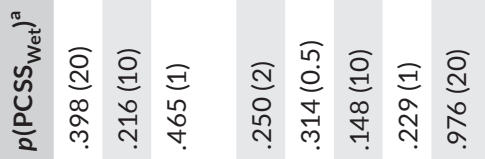

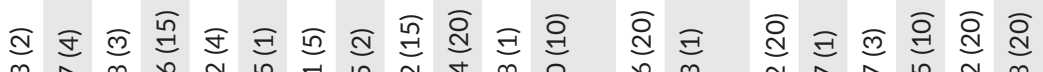

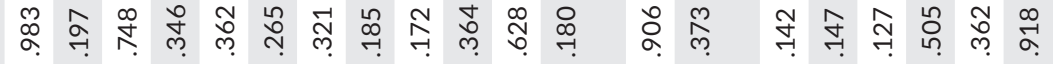

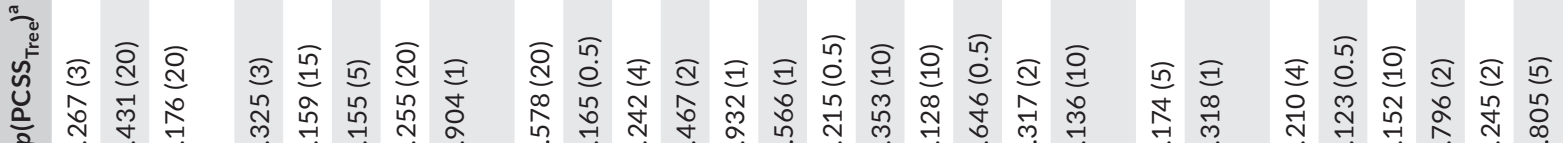

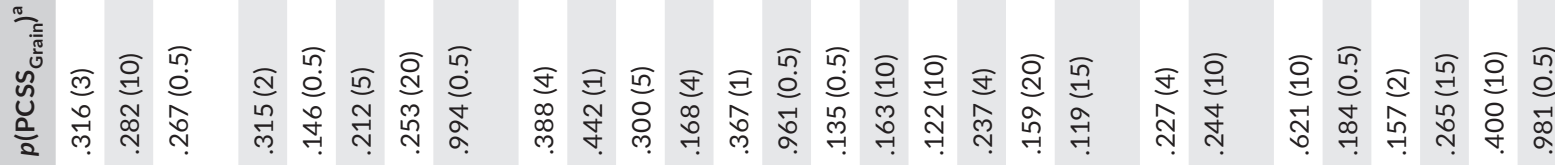

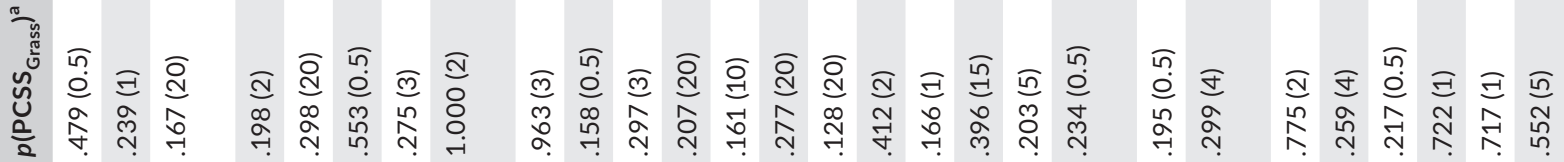

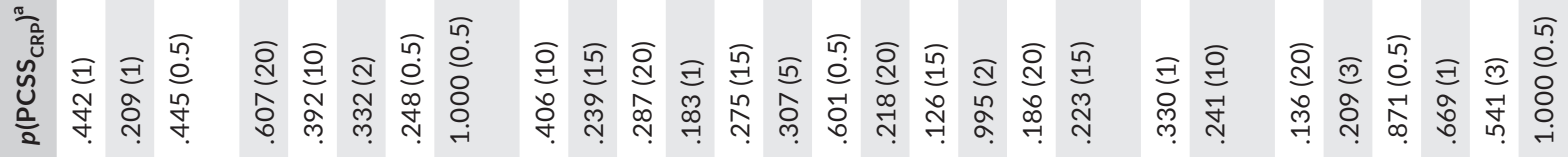

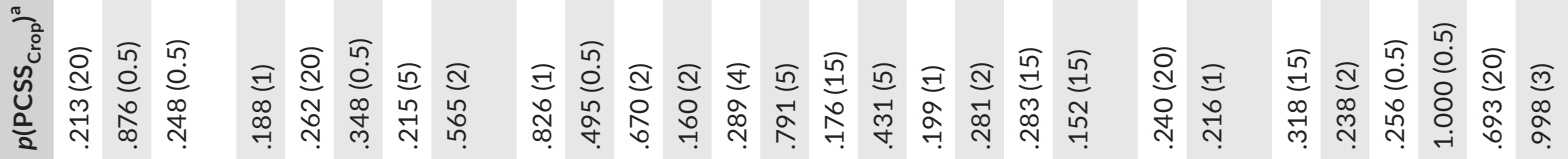

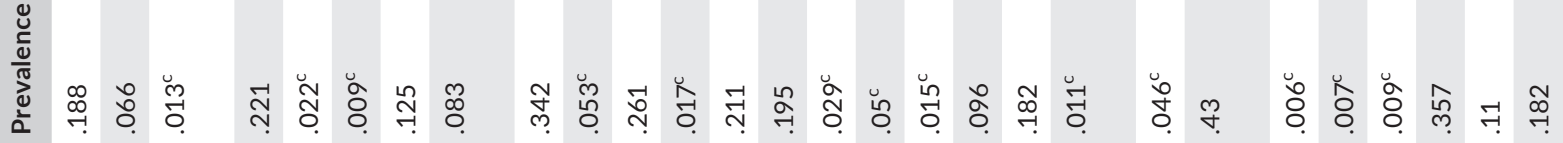
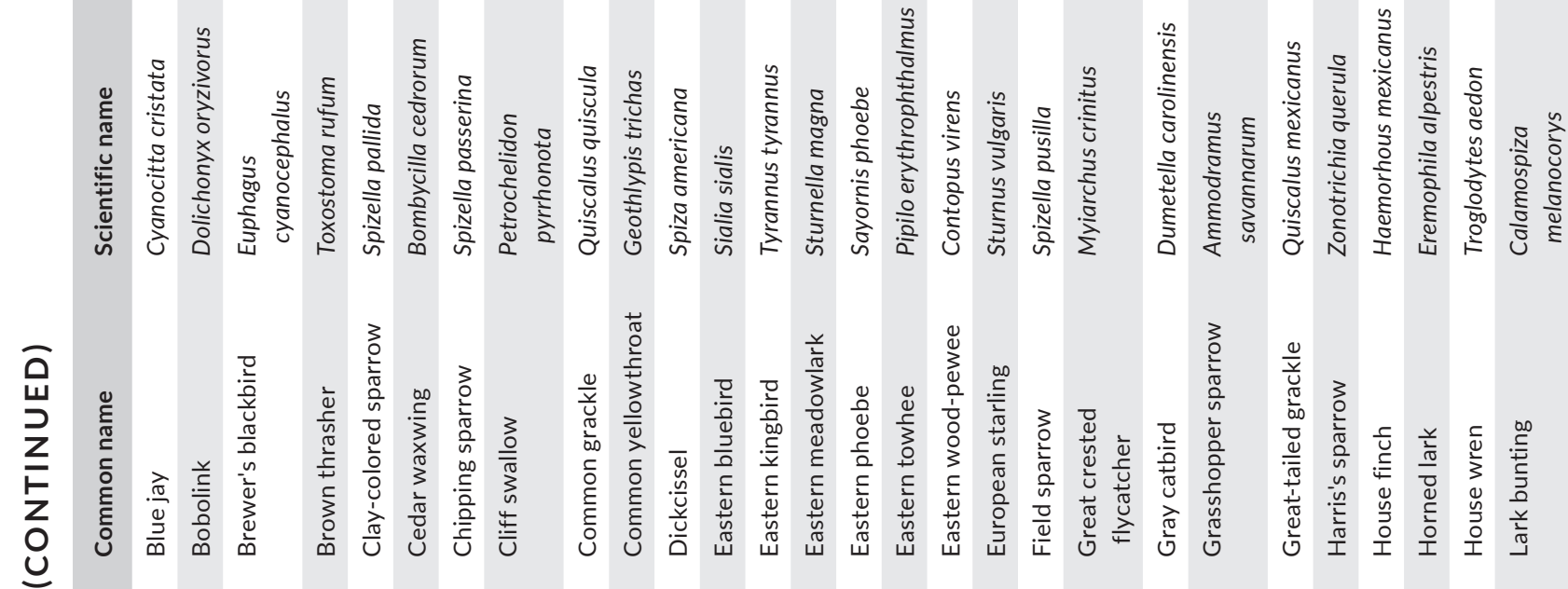


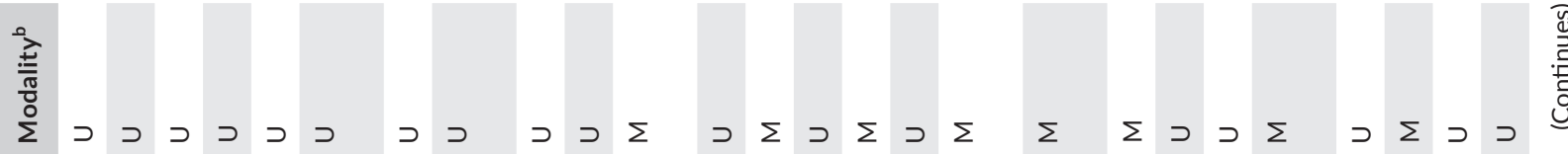

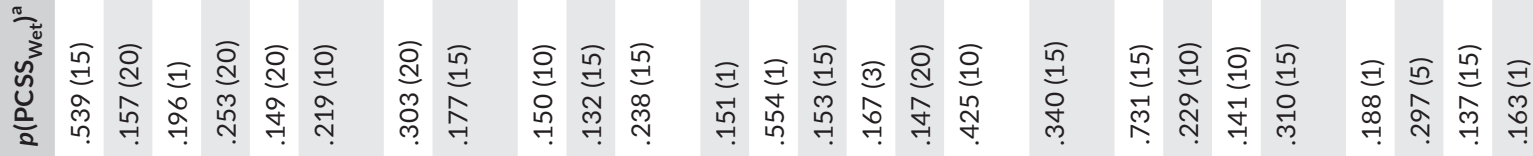

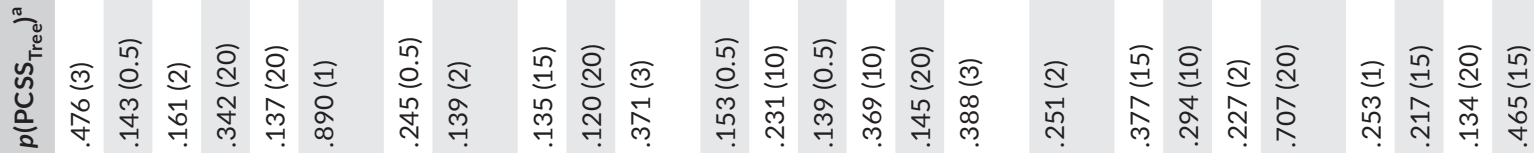

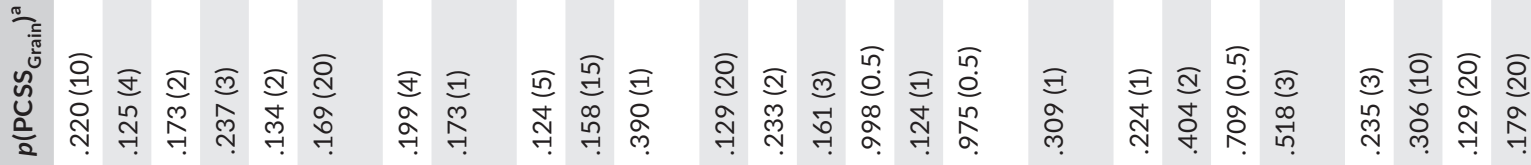

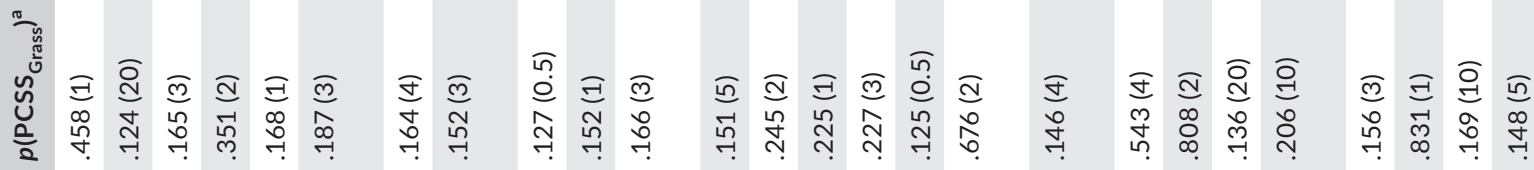

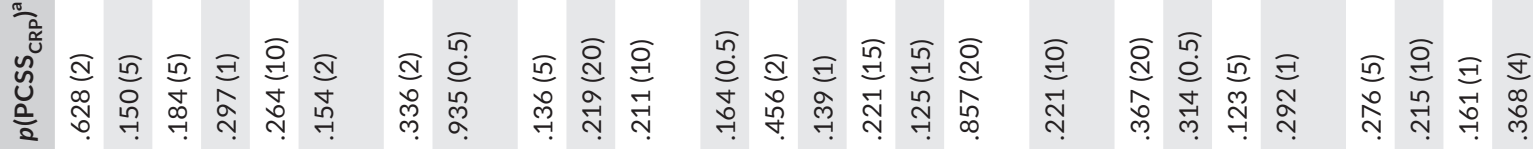

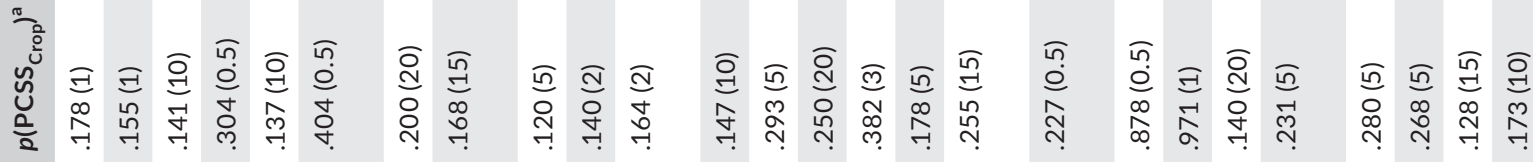

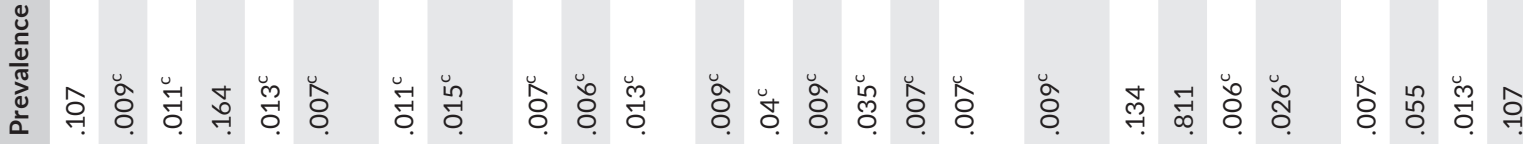
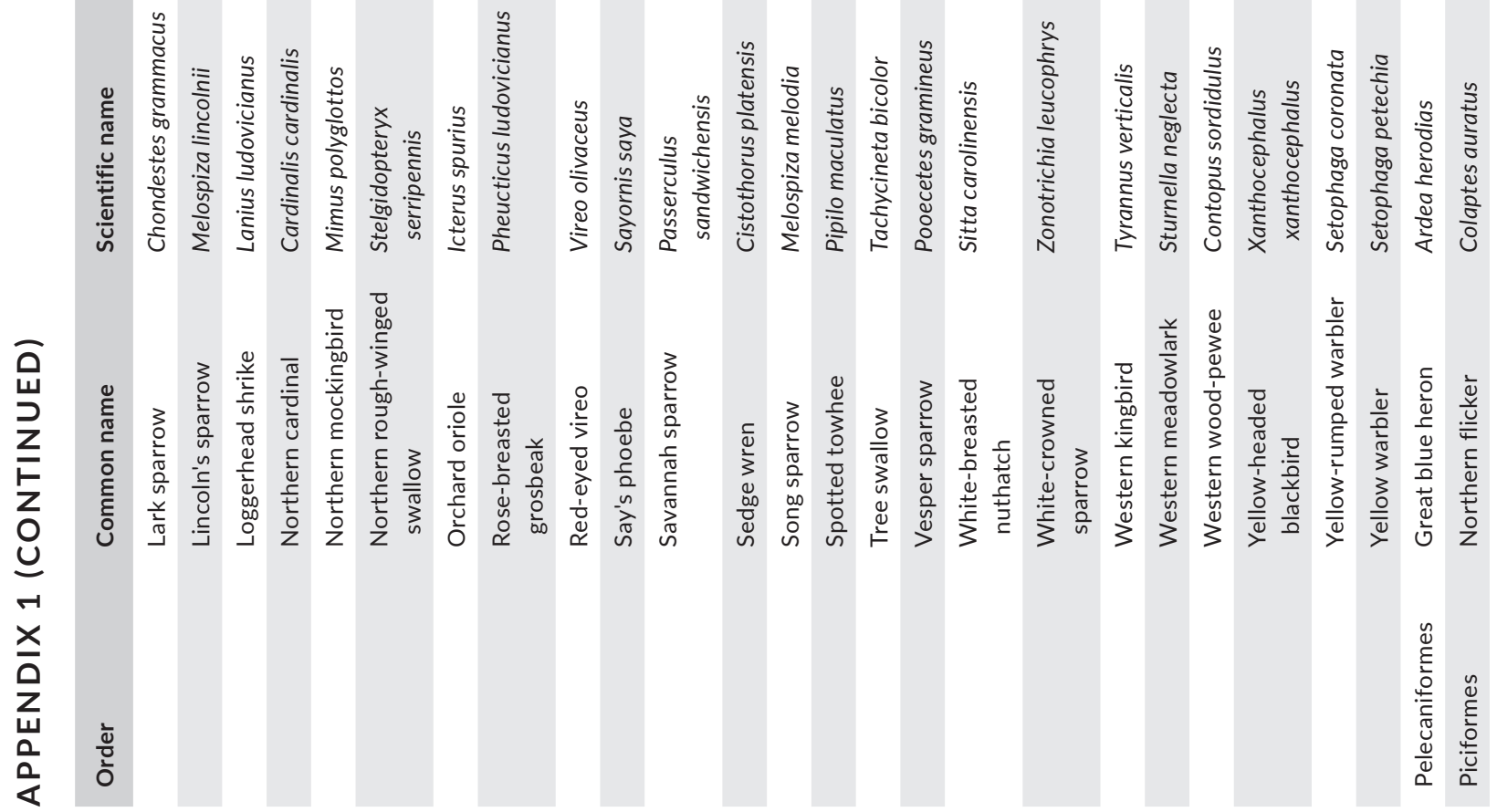


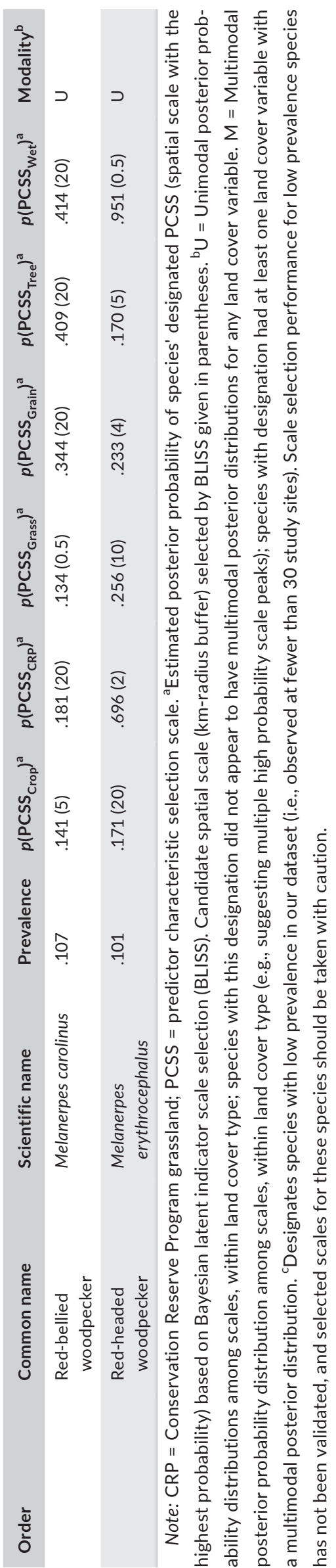


APPENDIX 2 VARIATION IN PROPORTIONS OF LAND COVER VARIABLES AT 544 STUDY SITES ACROSS NEBRASKA, USA, AT THE SMALLEST (500-M RADIUS) AND LARGEST (20-KM RADIUS) CANDIDATE SPATIAL SCALES EVALUATED WITH BAYESIAN LATENT INDICATOR SCALE SELECTION
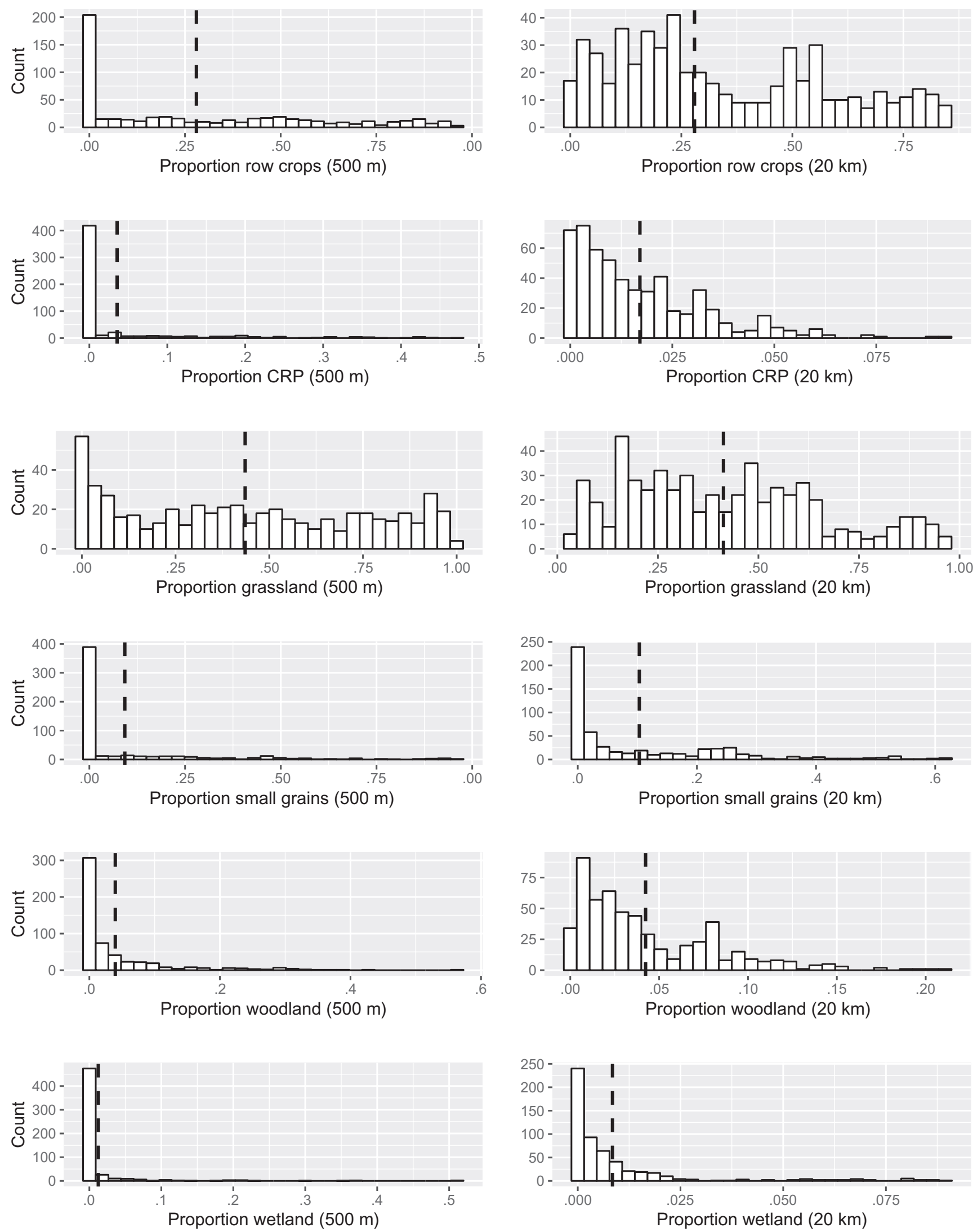